\title{
DISCUTINDO O OUTRO: A LITERATURA GÓTICA E A ALTERIDADE DO CORPO
}

Camila Mello ${ }^{1}$

\begin{abstract}
Resumo: O outro é fundamental a qualquer indivíduo; ele é espelho, reflexo, parâmetro. A tentativa de calar a diferença do outro gera intolerância, violência, e exige o fortalecimento de grupos minoritários contra a opressão desmedida. Este artigo traz um diálogo teórico sobre o conflito entre eu e outro, e uma análise da alteridade do corpo no gótico contemporâneo, através do romance Lady Oracle, de Margaret Atwood.
\end{abstract}

Palavras-chave: Minorias, discurso, o gótico, o corpo.

\section{I.}

Você recusa ser

(e eu)

um reflexo exato...

(Eating Fire, 7)

O outro é uma necessidade inegável. No entanto, necessidade negada com tanta frequiência: “o que os outros vão dizer não me interessa!". Sempre que escuto este discurso, minha reação é inevitável: uma leve vontade de rir baixinho, abaixo a cabeça e penso comigo "que negação vazia...”. A importância de não considerar o outro já revela a sua importância.

O outro é também um eu (ou "o outro é um outro eu”, Dostoievski completaria o trava-língua). A definição dos conceitos de eu e outro é fundamentalmente uma questão de referencial. Sob este ponto de vista, apesar de reconhecer a relevância no outro, penso que não há nada de especialmente enigmático em sua figura: ele é apenas um eu fora de mim que me influencia, e vice-versa. Ao longo da história da humanidade, no entanto, parece que esta definição que evoco de forma tão simples foi ignorada e substituída pelo abafamento do outro, quando muito distinto do eu. Mas calar outros nada mais é que aniquilar o eu de vários indivíduos; e é por causa deste fenômeno cruel que os movimentos de minorias ainda são necessários, e porque hoje escrevo um texto sobre o outro.

Toda esta história, resumida por mim como em uma resenha microscópica de um livro eterno, desemboca no presente trazendo uma pergunta: o que fazer com o outro, como tratá-lo, como sê-lo? Uma resposta é constante em toda a literatura que conheci até hoje: cuidado, muito cuidado com o outro! É preciso ter cautela e coragem para impor-se frente ao outro, meus livros me dizem. Apesar de perceber o outro de forma objetiva e simples, como descrevi acima, eu concordo com meus livros humildemente, porque reconheço que a relação entre eu e outro pode ser traumática. Até hoje, confesso

\footnotetext{
${ }^{1}$ Universidade Estadual do Rio de Janeiro. Mestrado em Literaturas de Língua Inglesa.

${ }^{2}$ Todas as citações deste texto foram traduzidas por mim.
} 
nunca sofri a monstruosa influência negativa e controladora do outro de maneira traumatizante. Sei, no entanto, de mil e uma estórias de repressão, violência, maltrato, injustiça, que fizeram da figura do outro um assunto tão delicado atualmente. Minha contribuição é o conhecimento. A supervalorização do outro é maléfica. É por pensar assim que me incomodam algumas idéias de Judith Butler sobre o poder do outro. $\mathrm{Na}$ "Introdução" de Bodies that Matter, por exemplo, ela relaciona discurso, normas, performance e materialidade em relação a sexo e gênero; mas o que me interessa é o efeito que a voz do outro exerce, na descrição da autora. Explicando sua tese em poucas palavras: o corpo é mobilizado por leis (normas sociais), e a mera citação de uma norma é suficiente para que um indivíduo tenha sua liberdade talhada. Butler se pergunta: "Até que ponto o discurso influencia o que ele nomeia através da citação de convenções autoritárias?" (BUTLER; 1993, 13). Logo em seguida, ela afirma que as leis mencionadas acima só funcionam porque são reiteradas constantemente pelas próprias ações que elas definem no ato do discurso. Diz, ainda, que a própria subjetividade (entende-se aí a tentativa de transgredir tais leis) só é possível porque as normas permitem, isto é, porque há um espaço previsto e controlado para a transgressão nas próprias leis de conduta social. Em minhas palavras: Butler indica que estamos presos ao que o outro dita. Eu percebo aí a supervalorização do outro, este sentimento de prisão claustrofóbica, de submissão inevitável, já que a própria quebra das regras é um movimento calculado por elas. Não pretendo afirmar que o mecanismo que a autora descreve é fictício, mas propaguemos uma outra visão: nós, e somente cada um de nós, podemos fugir de qualquer tipo de força opressora que tente nos subjugar, caso estejamos em condição de alteridade desprivilegiada. É possível formar uma proteção contra os ferimentos que o olhar e a voz do outro opressor causam, através do conhecimento e da articulação. Do conhecimento porque a ignorância tem sido, a meu ver, o maior inimigo das minorias e, sobretudo, das maiorias; da articulação porque nos casos em que há a relação de superioridade/inferioridade entre eu e outro, a união é um escudo social contra a dominação do opressor. Alguns grupos minoritários, felizmente, percebem a força potencial da união.

II.

As coisas

não se nomeavam; recusavam-se

a ser nomeadas por ele.

(Eating Fire, 40)

Mas a questão que Butler levanta, o poder do discurso, é interessante. Eu discordo do tom um tanto trágico-inevitável que ela confere ao tema, mas o ato de nomear é realmente uma atitude instintiva em relação ao outro. Na Literatura pósmoderna, em romances como Jasmine, de Bharati Mukherjee, e Stone Butch Blues, de Leslie Feinberg, encontramos uma lista de nomes destinados especialmente para o outro. No primeiro romance, a protagonista chama-se Jasmine/Jyoti/Jase/Jane/Kali, de acordo com sua localização e seu marido, isto é, quem a acompanha muda sua identidade com a intenção de "aliviar" sua alteridade: a nomeação pode torná-la menos estranha, mais passível de familiarização. Neste romance, a meu ver, a protagonista aceita estas mudanças não apenas porque se curva à domesticação que sofre, mas também porque vê a nomeação imposta como uma forma de proteção, já que a habilidade de moldar-se é seu maior trunfo. Neste caso, a mudança de nomes, a identidade maleável, conferida pelo opressor, apresenta um lado positivo, que não pode 
ser ignorado: o outro se adapta como um camaleão, e por mais que isso interfira em seus costumes, assegura sua sobrevivência.

O segundo romance, Stone Butch Blues, tem como protagonista Jess Golberg, uma stone butch - mulher que expressa seu gênero de forma masculinizada (gênero, não orientação sexual). Goldberg recebe vários nomes pejorativos nos ambientes heterossexuais em que se apresenta. Neste romance, o movimento não é o de familiarizar o outro estranho, mas sim o eliminá-lo, porque ele é muito distinto do eu, ele perturba a própria estabilidade do eu com a sua diferença. Não é por simples acaso que a personagem sofre estupros e espancamentos em diversos pontos da estória, sendo colocada no limite entre vida e morte repetidamente, tudo isso devido ao fato de que ela não segue o padrão de feminilidade das mulheres. Mas mais doloroso que ler este romance e imaginar tais situações, é saber que elas existem na realidade de vários indivíduos.

Trabalhando com o gótico literário, venho percebendo que na maioria das obras góticas e neogóticas também há um extenso vocabulário para designar o estranho, o excêntrico, o outro. Em Frankenstein, de Mary Shelley, a Criatura é chamada de besta, monstro, animal, Coisa; em Drácula, de Bram Stocker, o Conde é chamado de demônio, nosferatu, vampiro, homem, animal; em Hamlet, de William Shakespeare, o falecido pai de Hamlet é chamado de coisa, fantasia, aparição, imagem, ilusão, (pobre) fantasma, espírito. Cito todos estes exemplos para que o leitor perceba que qualquer manifestação do outro é marcada verbalmente, é "citada", utilizando o vocabulário de Butler; o discurso opressor, a procura por um termo que vá tentar explicar ou classificar o desconhecido é sintomática, na Literatura e também na vida.

\section{III.}

...mas se você olhar por mais tempo,

eventualmente

você vai conseguir me ver.

(Eating Fire, 2)

Mas muito além das palavras está o corpo, está a experiência do eu e do outro. Experiência vivida, para evocar a irresistível Simone de Beauvoir. O outro está mais evidente no discurso do corpo que no discurso da palavra, certamente. Na ficção ou na vida real, o impacto da cor da pele, do formato do corpo, do tipo de cabelo, da cor dos olhos é inegável e precede qualquer verbo. O outro é sempre o negro, é sempre o deficiente físico, o idoso, o homossexual, o não-nativo, a mulher. Incomoda-me muito colocar a mulher nesta lista, porque vejo tanta força sendo conquistada por nós, que já não me parece coerente citar-nos como "menor". No entanto, deixo-nos na lista porque sei que certas conquistas não são gozadas por todas nós. Gostaria muito de não ver as mulheres mais em lista alguma; na verdade, gostaria de não ter nenhum grupo sendo citado como o outro, desprivilegiado e humilhado.

Voltando à trilha do gótico literário, examinando-o em uma de suas manifestações contemporâneas, quero mostrar com o romance Lady Oracle, da canadense Margaret Atwood, de que forma o corpo caracteriza o outro fortemente, com mais força que outras características peculiares de cada indivíduo. Creio nisto porque, a meu ver, o que não está na pele pode passar desapercebido. A opção sexual, a religião, o passado cultural, nada disso necessariamente transparece na sua cor, na sua face, nos seus cabelos, suas roupas. Mas, por exemplo, a deficiência física marca a alteridade do indivíduo inegavelmente. De forma automática, nomeamos de "deficiência" qualquer 
diferença marcada na estrutura de um corpo. Para a protagonista de Lady Oracle, esta marca está no peso.

Focando a parte dois deste romance, conhecemos a infância de Joan Foster e entramos em contato com uma realidade complexa, na qual conflitos constantes com sua mãe e situações constrangedoras giram em torno de um problema central: a obesidade. Nas palavras de Julia Kristeva, Foster é um corpo abjeto porque ele "perturba a identidade, o sistema, a ordem. [Ele] não respeita fronteiras, posições, regras. [Ele é o] entre-posições, o ambíguo, o composto." (KRISTEVA; 1982: 4). Em minhas palavras, o abjeto é o outro. Foster é indivíduo abjeto porque transborda limites. O corpo marca o outro de forma categórica.

Foster então nos fala sobre seu corpo:

Eu não era magra, e esta é uma das razões pela qual minha mãe nunca me perdoou. Antes eu era apenas fofa; nas primeiras fotografias no álbum de mamãe eu era um bebê saudável, tão gordinha quanto os outros, e o peculiar é que eu nunca estava olhando para a câmera; ao invés, eu estava tentando colocar alguma coisa na minha boca: um brinquedo, uma mão, uma garrafa. As fotos continuaram em série; apesar de não ter ficado mais rechonchuda, eu não perdi aquilo que é chamado de gordura de bebê. Quando eu fiz seis anos as fotografias pararam abruptamente. Isto deve ter acontecido quando minha mãe desistiu de mim, porque era ela que costumava tirar as fotos; talvez ela não queria mais registrar meu crescimento. Ela decidiu que eu não daria certo na vida. (Lady Oracle, 39)

A característica grotesca, excessiva, e porque não, gótica, do corpo da personagem é anunciada. Há profundas conseqüências sociais e psicológicas para o indivíduo que é marcado como o ser estranho. O embate entre eu e outro que leva às relações de opressão, podem começar na própria família, como está exemplificado na citação acima. O corpo de Foster é excessivo porque ele acumula em si o que ela não pode vivenciar: a falta de uma estrutura familiar e emocional alimenta a sua obesidade; sua obesidade gera desequilíbrio familiar e emocional. A relação de opressão e submissão que nasce da simples diferença entre eu e outro é como um ciclo vicioso que aprisiona os indivíduos deste esquema binário, desfavorecendo um dos lados.

Foster encontra-se, portanto, em um mecanismo de punição de seu corpo. Esta punição é exercida por outros indivíduos, que a julgam e a maltratam por ser uma menina obesa, mas também por si própria durante sua infância, porque ela não consegue bloquear tais pressões externas: ela questiona sua situação mas suas reflexões a arrastam cada vez mais para o silêncio. Não é surpresa que o romance comece com a descrição da morte que Foster forja para si. A morte encenada é sinal da necessidade desesperada de renascer, e, ao renascer, deixar de viver como um outro repugnante. Há outros sinais desta necessidade, por exemplo, as roupas de Foster, seu constante estado de mutação na vida adulta, o corte e queima de seus cabelos, e as obras literárias que ela cria. Este comportamento na vida adulta de Foster reforça a crítica que fiz sobre a idéia do corpo como sítio de controle inevitável, apresentada por Butler: Foster torna-se ciente de seu corpo e de sua alteridade, e é através das tentativas de mudança radical que ela busca resolver seus conflitos. Ela destrói sua identidade e constrói uma nova na esperança de libertar-se dos obstáculos que a alteridade impõe. A situação aqui, portanto, é contrária a de Jasmine, pois a própria personagem que recebe o status de outro se modifica em busca de sobrevivência.

Em algumas passagens no romance, a personagem tenta se reconstruir através da negação. Por exemplo: após perder peso, ela não conta ao marido que era obesa; mesmo 
quando ele pergunta quem é a menina gordinha em uma fotografia que encontra, ela responde "Eu não gostava dela. Ela estava sempre tentando me dizer como viver minha vida" (Lady Oracle, 88), mas nós sabemos que a menina da foto é a própria Foster. Esta negação, no romance, não significa que Foster esqueceu e superou seu passado, e sim que ela ainda é assombrada por ele, ela não conseguiu se livrar das consequiências psicológicas de ser o outro dentro de sua sociedade, mesmo que seu corpo tenha mudado e que, na vida adulta, ela consiga sobreviver.

A circunstância que leva Foster a perder peso é outro componente intrigante no romance. Sua Tia Lou, mulher mais obesa que Foster, a única fonte de afeto e segurança de nossa protagonista, impõe a perda de peso à sobrinha em seu testamento:

Tia Lou realmente tinha me deixado algum dinheiro. Dois mil dólares, na verdade, o que era bastante naquela época, para alguém da minha idade. Mas havia uma condição: eu só iria ter o dinheiro se reduzisse de tamanho, e Tia Lou havia até especificado o peso correto. Eu tinha que perder cem quilos. (Lady Oracle, 144)

O que pensar da atitude de Tia Lou? E por que Foster resolve perder peso apenas após a morte da tia, se sua mãe já havia pedido o mesmo tantas outras vezes? Tanto tia quanto mãe parecem ter o mesmo desejo - que Foster perca peso - mas a meu ver, há uma diferença crucial: o pedido da mãe nasce porque ela quer que sua filha deixe de ser o outro e se encaixe em um modelo feminino mais aceito, mais "normal"; a tia pede a perda de peso porque sabe o que é ser o outro naquela sociedade, ela conhece as conseqüências desta posição, e não quer que a sobrinha sofra o mesmo. Minha especulação é esta, pois é o que me parece mais óbvio em relação ao pedido da tia em seu testamento. Foster também percebe tal distinção entre as intenções da tia e da mãe, e só perde peso após a morte de Lou. Neste momento recordo as palavras Paula Moya: "o simples fato de passar por uma experiência de opressão não é suficiente para entendermos a situação de opressão de outra pessoa" (MOYA; 1996: 148). Claro, a experiência da tia não a faz entender a experiência de Foster por completo. Mas acredito que, neste romance, trata-se de uma atitude extremamente compreensível: é inato do ser humano o instinto de proteger, e, ao proteger, privar outros indivíduos de passarem por certas experiências, porque se acredita que esta ou aquela situação trará sofrimento. Mas é interessante notar que Foster, mesmo sofrendo interferências divergentes, acaba tomando uma decisão final sem a contribuição direta de ninguém:

Em meus momentos de lucidez, eu pensava sobre sua outra mensagem para mim, aquela em seu testamento. Como eu deveria interpretá-la? Será que minha tia não me aceitava de verdade pelo que eu era, como eu acreditava - que ela me achava muito grotesca, que para ela eu também não daria certo na vida? $\mathrm{Ou}$ será que a vida seria mais fácil se eu fosse mais magra? Ela me ofereceu dinheiro para fugir, escapar da minha mãe, era o que eu queria; mas me forçando a entrar na linha, ou pelo menos foi assim que pareceu.

Um dia, quando eu estava sentada na cama, folheando um das estórias de detetives do meu pai, eu acabei olhando de relance para o meu corpo. Eu havia tirado o cobertor, e minha camisola estava desajeitada. Eu não costumava ver meu corpo, em um espelho ou de qualquer outro modo; eu dava umas olhadas em algumas partes uma vez ou outra, mas o todo era muito impressionante. Ali, olhando para minha cara, estava minha coxa. Ela era enorme, era como um membro doente, do tipo que você vê em fotos de nativos das selvas; ela se espalhava por todos os lados, como uma planície fotografada, a carne não era verde, mas azulada, com veias como rios. Era do tamanho de três coxas 
normais. Eu pensei, Isso é realmente a minha coxa. É mesmo, e aí pensei, Isso não pode mais continuar assim. (Lady Oracle, p. 117)

Temos aí, como eu já havia mencionado, o caráter grotesco do corpo de Foster. $\mathrm{O}$ excesso e a monstruosidade gótica a fazem ser vista durante toda sua juventude como um outro repugnante que deve ser repelido. Mas além disso, esta passagem mostra um mecanismo interessante: estando na posição de outro, é difícil um indivíduo conseguir superar as consequiências de seu status. A cooperação e a integração, como também já mencionei, são fundamentais para que o indivíduo em posição desprivilegiada consiga encontrar meios para libertar-se. A tia funciona como incentivo para que Foster perceba sua condição como outro e veja uma possível saída para seu sofrimento. Ela percebe que seu corpo excessivo e grotesco sofria com suas experiências. Ela decide perder peso e dar uma guinada radical em sua vida: ela sai de casa e foge da posição humilhante de outro. Só a leitura do romance pode nos dizer até quando esta escapatória é eficiente para a protagonista.

IV.

Eu vejo você

ver minha face

indiferentemente,

e no entanto com a mesma curiosidade

que você teria ao admirar

uma parte recém-descoberta

do seu próprio corpo...

(Eating Fire, 9)

O gótico é o outro da Literatura; o outro sempre foi tema fundamental para o gótico. A diferença pode nos repugnar, mas, curiosamente, ela também pode seduzir. Freddy Krueger do filme A Hora do Pesadelo me dá nojo; o Conde Drácula de Francis Ford Coppola me fascina. Atração e repulsão: o movimento magnético que comanda duas estratégias fundamentais da literatura gótica: terror e horror. É na figura do outro e na exploração destes dois movimentos, atração e repulsão, que o gótico trabalha as relações humanas. É exatamente esta forma peculiar de inserir a figura do outro em sua narrativa - não só o outro como indivíduo, mas também um sentimento, um fenômeno, um conceito totalmente excêntricos - que fez com que o gótico literário fosse sempre marginal a toda uma tradição literária, que abordava temas em comum, mas respeitando os limites do realismo. Portanto, sim, o gótico é o outro literário, uma condição que o próprio gênero alimenta com suas peculiaridades e estratégias fundamentais.

\section{Referências Bibliográficas}

ATWOOD, Margaret. Lady Oracle. New York: Anchor Books, 1998.

ATWOOD, Margaret. Eating Fire: Selected Poetry, 1965 - 1995. London: Virago, 1998.

BUTLER, Judith. Bodies that Matter. New York: Routledge, 1993.

FEINBERG, Leslie. Stone Butch Blues. New York: Firebrand Books, 1993.

KRISTEVA, Julia. Powers of Horror: an Essay on Abjection. New York: Columbia University Press, 1982.

MUKHERJEE, Bharati. Jasmine. New York: Grove Weidenfeld, 1989.

SHAKESPEARE, William. Hamlet. London: Penguin, 2001. 
SHELLEY, Mary. Frankenstein. London: Penguin, 1994.

STOCKER, Bram. Dracula. New York: Penguin, 1994.

\begin{abstract}
The other is fundamental to any individual; it is a mirror, a reflection, a parameter. The attempt to abolish the difference of the other leads to intolerance, violence, and demands the strengthening of minority groups against oppressions. This article brings a theoretical dialogue on the conflict between the self and the other, and an analysis of the otherness of the body in contemporary Gothic, through the Margaret Atwood's Lady Oracle.
\end{abstract}

Keywords: Minorities - discourse - the Gothic - the body. 